\title{
SEMANTIK DES VERBALEN PRÄFIXES VER- IN DER DEUTSCHEN GEGENWARTSSPRACHE UND SEINE ENTSPRECHUNGEN IM SERBISCHEN*
}

Der vorliegende Beitrag beschäftigt sich mit dem Präfix ver- bei deutschen Verben und seinen serbischen Entsprechungen. Anhand eines ausgewählten Korpus werden die ver-Verben analysiert und nach ihrer semantischen Leistung eingeteilt. Der Vergleich mit der serbischen Seite soll wertvolle Erkenntnisse bezüglich der Übersetzungs- aber auch der Deutungsmöglichkeit der ver-Verben liefern. Die auf diese Weise gewonnenen Ergebnisse können im Rahmen des DaF-Unterrichts ihren festen Platz finden.

Schlüsselwörter: Semantik, Präfix, Verben, ver-, deutsch-serbisch.

\section{Einleitung}

1.1 Das Ziel des vorliegenden Beitrages ist es, das verbale Präfix ver- zu beschreiben, gleichzeitig aber auch die Ähnlichkeiten und Unterschiede im Bezug auf die Semantik seiner serbischen Entsprechungen festzustellen und zu analysieren. Die dem Beitrag zugrundeliegenden Methoden sind sowohl die deskriptiv-analytische, als auch die kontrastive Methode. ${ }^{1}$ Das Korpus bilden 391 deutsche Verben, die das Präfix ver- beinhalten, und ihre Entsprechungen im Serbischen. ${ }^{2}$ Die Verben wurden dem Enzyklopädischen deutsch-serbischen Wörterbuch von Dr. Svetomir Ristić und Jovan Kangrga aus dem Jahre 1963 entnommen. Da eine anderweitige Analyse den zur Verfügung gestellten Rahmen sprengen würde, wurden nur jene ver-Verben analysiert, die weder Substantive (z. B. verarzten, verdunsten) noch Adjektive (z. B. vergrößern, verdünnen) als Stamm haben. Ebenfalls wurden alle ver-Verben, die im Grunde Doppelpräfixe bzw. eine Kom-

istbogner@gmail.com

Die kontrastive Methode hat sich im Laufe der letzten vier Jahrzehnte als eine äußerst hilfreiche Methode bewährt, da sie die Möglichkeit bietet, gewisse Eigenschaften innerhalb einer Sprache zu erkennen, die eventuell in einer einzelsprachlichen Untersuchung nicht deutlich genug wären. Somit könnte man sagen, dass die kontrastive Methode als Ergänzung zur einzelsprachlichen Beschreibung angesehen werden kann (vgl. Rein, 1983: 7).

2 Nachvollziehbarerweise ist die Zahl der serbischen Entsprechungen um einiges größer, da ein im Deutschen existierendes ver-Verb oft mehr als nur eine serbische Entsprechung aufzuweisen hat. Viele Verben sind polysem, m.a.W. mehrdeutig, was die Analyse nicht wenig erschwert. 
bination aus Verbpartikel und Präfix (etwa verunreinigen, verabschieden) oder Fremdwörter (z. B. verkapseln, verabsolutieren) beinhalten außer Acht gelassen. Verben, die ohne ver- keine Bedeutung haben (etwa vergessen, verletzen, verlieren) oder nicht (mehr) im Gebrauch sind ( z. B. versparen) konnten gleichermaßen an dieser Stelle nicht in Betracht gezogen werden.

1.2 Präfixe (von lat. praefigere, vorn anheften', Wahrig, 2009: 273) sind, einfach ausgedrückt, Affixe, die dem Grundwort vorangestellt werden (vgl. Hentschel, \& Weydt, 2003: 23). Der Duden definiert sie als „Ableitungssilbe[n] [die] vor ein Wort [oder] einen Wortstamm gesetzt [werden]“" (DUDEN, 2005). Diese gebundenen Einheiten können mit Verben, Substantiven oder aber auch Adjektiven verbunden werden. ${ }^{3}$ Für den vorliegenden Beitrag sind nur die Ersteren, nämlich die Verben, von Belang.

\section{Präfixe und ihre Leistungen in der deutschen Sprache}

2.1 Im Unterschied zu den Suffixen, die zwar auch eine Möglichkeit der Wortbildung darstellen, wenn auch im beschränkten Maße, sind die Präfixe stark produktiv, insbesondere, wenn es um ihre Verbindung mit Verben geht. ${ }^{4}$ Eichinger hebt hervor, dass ,die Präfixbildung beim Verb [...] die einzige Wortbildungsart bei dieser Wortart [sei], bei der kein Zweifel am Wortcharakter der entstehenden Konstruktion herrsche" (Eichinger, 2000: 102).

2.2 Nach Grebe nehmen die Präfixe eine Mittelstellung zwischen den Zusammensetzungen und Ableitungen ein und stellen nach Wortzahl und nach ihren Leistungen eine sehr große Gruppe der Wortbildungen dar (vgl. Grebe, 1959: 397). Für Homberger ist ein Präfix ,dt. Vorsilbe, ein an einen Wortstamm gebundener Wortteil, der diesem vorangeht und nicht allein gebraucht werden kann" (Homberger, 2003: 405). In diesem Zitat sind die wichtigsten Eigenschaften des Präfixes gegeben: Es handelt sich demnach um ein Wortteil, das

1. an einen Wortstamm gebunden ist,

2. dem Wortstamm immer vorangeht und

3. nicht allein gebraucht werden kann.

Weiterhin wird angeführt, dass die Präfixe die Aktionsart einer verbalen Fügung bestimmen können: erblühen - blühen - verblühen (ebd.).

Beispiel hierfür wären etwa zerlegen (für Präfix + Verb), Misserfolg (für Präfix + Nomen) und unverständlich (für Präfix + Adjektiv).

4 Präfixe könne aneinandergereiht bzw. multipliziert werden (wie beispielsweise in ururalt oder Ururururenkel), was z. B. bei Suffixen nicht möglich ist (vgl. Motsch, 2004: 284; Donalies, 2005: 27). Durch das Zusetzen eines Präfixes verändert sich in der Regel die Semantik des jeweiligen Verbs. So existieren z. B. zum Verb fahren auch die Verben verfahren, befahren, ausfahren, durchfahren, erfahren, widerfahren usw. Können bei den ersteren Verben (verfahren, befahren, ausfahren, durchfahren) deren Bedeutungen noch einigermaßen aus dem ursprünglichen Verb geschlossen werden, ist dies bei den restlichen zwei hier angeführten Verben (erfahren und widerfahren) nicht mehr möglich. 
2.3 Bußmann zählt die Präfixe zu den Wortbildungselementen und stellt die Frage, ob die Präfixe eine Wortart in eine andere Wortart zu überführen vermögen (vgl. Bußmann, 1990: 598). Dafür würden die ,von Substantiven oder Adjektiven abgeleiteten Verben wie vernarben, entkalken, befeuchten, erfrischen, da die einfachen Verben *narben usw. nicht existieren" sprechen (ebd.). Aber durch Überprüfung dieser Angaben im Wörterbuch ${ }^{5}$ stellt sich heraus, dass die Verben narben, kalken, feuchten, frischen doch existieren. Die folgende Kurzanalyse soll die Frage beantworten, ob die Präfixe auch das Vermögen haben, eine Wortart in eine andere zu überführen:

1. der Kalk $>$ kalken $=$ mit einer Mischung aus gelöstem Kalk und streichen ent-kalken $=$ von Kalkbelagerungen befreien

Das vom Substantiv Kalk abgeleitete Verb kalken hat die Bedeutung: mit Kalk (eine Wand) streichen, das präfigierte Verb entkalken (ent + Kalk) hat aber nicht die Bedeutung eine Mischung aus dem gelösten Kalk zu entfernen, sondern eine Kalkbelagerung entfernen. In diesem Fall zeigt das Präfix ent- sein überführendes Vermögen in eine andere Wortart: Präfix + Substantiv $=$ Verb.

2. frisch $>$ frischen $=$ a) im Hüttenwesen: Roheisen durch Oxidation der begleitenden Bestandteile in Stahl umwanden

b) Jägersprache: Junge werfen

er-frischen $=$ neu beleben, jmdm. neue Frische bringen

Das vom Adjektiv frisch abgeleitete, nicht präfigierte Verb frischen bezeichnet einen Prozess im Hüttenwesen und in der Jägersprache bezeichnet es: junge Tiere zur Welt bringen. Durch die Zusammensetzung von Präfix und Adjektiv (er-frischen) entsteht ein neues Verb, das nur einen etymologischen Zusammenhang mit dem Grundwort darstellt, aber keinen semantischen. Das überführende Vermögen zeigt das folgende Schema: Präfix + Adjektiv $=$ Verb.

3. die Narbe (< wgerm. adjektiv: *narwa $=$ eng $)=$ auf der Hautoberfläche sichtbare Spur einer verheilten Wunde

narben $=$ in der Gerberei: (von Fellen enthaaren), sodass der Narben zum Vorschein kommt

ver-narben $=$ beim Heilen eine Narbe bilden

Bei diesem Beispiel handelt es sich um ein westgermanisches Adjektiv *nar$w a=e n g$, das durch Substantivierung seit dem 12. Jh. in der Form narwe (= Nehrung, Enge) bezeugt ist. Nach den etymologischen Wörterbüchern ist festzustellen, dass aus der narwe durch mitteldeutschen Einfluss Narbe entstanden ist, von welcher wiederum das in den Gerbereien benutzte Verb narben abgeleitet ist. Es bleibt aber unklar, ob das präfigierte Verb vernarben durch Präfigierung aus dem Substantiv Narbe oder aus dem Verb narben herausgebildet ist. Jedenfalls besteht auch hier die Wahrscheinlichkeit, dass das präfigierte Verb unmittelbar aus dem Substantiv durch Präfigierung abgeleitet ist.

Für diese Analyse wurde durchgehend das Große Deutsche Wörterbuch von DUDEN (2000) verwendet. Daher wird die Quelle der Lemmata im Weiteren nicht angegeben. 
Aufgrund der oben angeführten Beispiele konnte bewiesen werden, dass Präfixe zur Überführung einer Wortart in eine andere dienen können.

\section{Das Präfix ver-aus diachroner Sicht}

Für das Verständnis gewisser Bedeutungsmöglichkeiten des Präfix ver- ist es wichtig zu erfahren, wo die Wurzeln dieses Präfixes liegen. Dadurch soll auch seine Polyfunktionalität verständlicher werden. Die Etymologie des Präfixes ver- geht auf die indogermanischen Wurzeln *per[i]-, *pr-, *pro- zurück, die in den indogermanischen Sprachen sehr oft vorkommen und zahlreiche Zusammensetzungen mit Substantiven und mit Verben bilden.

3.1 Im Griechischen: Das Griechische peri ${ }^{6}\left(<^{*}\right.$ per[i]-) kommt sowohl als Adverb als auch als Präposition vor:

a) Adverb: peri = ausgezeichnet (,изванредно'), rundherum (,унаоколо'), über

b) Präposition: peri

$$
\text { (Маß) (,преко [мере]'), sehr (,веома') }
$$

(mit Genitiv) = herum (,около'), um (,око'), über (,o'), wegen (,ради')

(mit Dativ) = an (,при'), auf (,на'), bei (,код'), neben (,крај')

(mit Akkusativ) = betreffs (,што се тиче'), gegenüber (,према'), in (,y')

(Gorski, \& Majranić, 1976: 325).

Diese kleine Übersicht zeigt, dass das Präfix/ die Präposition im Griechischen auch mehrere Bedeutungsvarianten hatte. ${ }^{7}$ Als Präfix ist peri sehr frequent: aiero $=($ er)greifen (,пограбити') (ebd.: 11), peri-aireo = zerstören (,разрушити') (ebd.: 326).

3.2 Im Lateinischen: Hier existieren zwei Varianten - per und por, wobei per als Präfix, als Suffix und als Präposition mit dem Akkusativ vorkommt, während por nur als Präfix erscheint. ${ }^{8}$

3.2.1 per als Präfix $=$ durch, zer-;

per-agrare durch-wandern (,обићи, пропешачити')

per-fringere zer-brechen (,разломити')

3.2.2 per als Suffix = parum-per auf kurze Zeit (,на кратко време')

3.2.3 per als Präposition:

a) Lokal: per orbem in der ganzen Welt (,на целом свету')

b) Temporal: per somnium im Traum (,y сну')

c) Instrumental: certiorem fieri per nuntios durch Boten benachrichtigt werden (,бити обавештен преко гласника')

d) Modal : per litteras schriftlich (,писмено') (Langenscheidt, 2001).

3.2.4 por: kommt im Lateinischen nur als Präfix vor und wird bedeutend weniger verwendet als per.

Aus arbeitstechnischen Gründen werden die griechischen Wörter in lateinischer Transkription wiedergegeben. Eine eingehendere Analyse vom peri würde schon den Rahmen dieser Studie überschreiten.

Die folgende Darstellung stellt eine gekürzte Version dar, da im Langenscheidts-Wörterbuch (2001) 14 Varianten angegeben sind. 
por-rigo ausdehnen (,испружити')

por-tendo vorhersagen (,прорицати’) (vgl. Langenscheidt, 2001).

3.3 Im Germanischen-Gotischen ${ }^{9}$ : Aus der indogermanischen Wurzel *per[i](Griechisch: peri, Lateinisch: per) sind durch die Germanische Lautverschiebung die gotischen Formen fair $^{10}$ - und faúra ${ }^{11}$ entstanden (vgl. Bogner, 2010: 23-27; Feist 1923: 102, 107).

3.3.1 Die Form *fair- erscheint im Gotischen als Präfix:

fair-aihan teilhaben an (,имати удео')

fair-greip-an* ergreifen (,зграбити')

fair-hai-t-an* verheißen (,обећати')

3.3.2 Die Form faúra erscheint im Gotischen als Adverb (lokal und temporal), als Präposition mit Dativ und als Präfix (vgl. Krause, 1953: 277).

3.3.2.1 Als Adverb:

a) lokal: faúra vorn (,испред')

b) temporal: faúra vorher (,пре')

3.3.2.2 Als Präposition mit Dativ:

a) lokal: faúra andwairpja Angesicht (,лицем у лице')

b) temporal: faúra mis vor mir (,пре мене')

3.3.2.3 Als Präfix:

faúr-stásseis Vorsteher (,начелник')

faúr-a-ga-sat-jan* vorstellen (,представити') (Köbler, 1989: 122).

3.4 Im Althochdeutschen: Es ist zu bemerken, dass das Präfix ver- im Althochdeutschen sehr aktiv ist - im Wörterbuch von Gerhard Köbler sind über $300 \mathrm{Be}$ lege hierfür angegeben (vgl. Köbler, 1993: 233-234):

far-geban geben, schenken (,даровати')

fir-neman wegnemen (,одузети')

3.5 Im Mittelhochdeutschen: Die Verwendung vom Präfix ver- erreicht schon in der mittelhochdeutschen Zeit solche Ausmaßen, dass man dem, wie für das Neuhochdeutsche, eine Sonderstudie widmen konnte:

ver-pflegen aufgeben (,напустити')

ver-liesen verlieren (,изгубити')

3.6 Abschließend kann festgestellt werden, dass das Präfix ver-, bzw. seine Wurzeln sowohl im Indogermanischen als auch im Germanischen sehr frequent waren und schon in den vorangehenden Phasen der deutschen Sprache mehrere Bedeutungsvarianten hatten, was einiges bezüglich der heutigen Bedetungsvarianten erklärt. Es sei an dieser Stelle festgehalten, dass die meisten heutigen ver-Verben aus dem gotische $\mathrm{fra}$ - entstanden sind.

$9 \quad$ In der folgenden Darstellung wird das Gemeingermanische das Gotische repräsentieren und die hochdeutschen Belege werden im Alt- und Mittelhochdeutschen dargestellt.

10 Das /e/ wird im Gotischen mit < aí> bezeichnet (Braune, 1952: 16).

11 Das /o/ wird im Gotischen mit <aú> bezeichnet (ebd.: 17). 


\section{4. Überblick zum Forschungsstand des Präfixes ver-}

Untersuchungen zu Präfixen allgemein gab es und gibt es immer noch in nicht geringem Umfang. Im Hinblick auf das Präfix ver- sind v. a. die Arbeiten von I. Kühnhold $^{12}$, E. Tellenbach ${ }^{13}$, W. Fleischer, \& I. Barz ${ }^{14}$ und nicht zuletzt auch von G. Mungan ${ }^{15}$ zu erwähnen. Erwähnenswert ist, dass die ersten Arbeiten zu diesem Thema am Anfang der 1970er anzusiedeln sind, demnach kann man von einer 40-jährigen „Tradition“ hinsichtlich der Beschäftigung mit dem Präfix ver- sprechen. Wie aber aus dem kurzen Überblick zu erkennen ist, sind diese Arbeiten und Forschungen größtenteils in den Rahmen der einsprachigen Untersuchung zu stellen. Erst in den letzten zwei Jahrzehnten ist man zu zweisprachigen Untersuchungen intensiver übergegangen. Hierzu sei etwa die Arbeit von S. Sarlov erwähnt - „Zur Semantik einiger ver-Verben und ihrer bulgarischen Entsprechungen" aus dem Jahre 1992.

\section{Semantische Leistungen des verbalen Präfixes ver-}

5.1 Das Präfix ver- gehört zu den sogenannten echten oder untrennbaren Präfixen (vgl. Eisenberg, 2004: 254-255). ${ }^{16}$ Fleischer, \& Stepanowa stellen Verben mit diesem Präfix in die Gruppe I, d. h. in jene Gruppe der präfigierten Verben, in welcher sich untrennbare „Wortbildungskonstruktionen mit den Präfixen be-, ent-, er-, zer-" und auch ver- befinden (Fleischer, \& Stepanowa, 1985: 137-139).

5.2. Wenn es um die semantischen Leistungen des Präfixes ver- bei Verben geht, so werden in der Fachliteratur unterschiedliche Meinungen vertreten. Einige wenige, etwa Berthele und Eisenberg, meinen, dass das Präfix ver- keine spezifische semantische Leistung besitzt (vgl. Berthele, 2006: 47). Die meisten sehen das anders und sind der Meinung, dass es sogar mehrere semantische Varianten gäbe, die aber, bei genauerem Betrachten, nur einige semantische Grundleistungen repräsentieren, welche folgendermaßen zusammengefasst werden könnten:

12 Kühnhold (1973) sondert neun Funktionen des verbalen Präfixes ver- aus und stellt dabei ins Zentrum ihrer Einteilung die perfektive Funktion von ver-. Neben den semantischen Kriterien bezieht sie aber auch die morphologisch-syntaktischen, nämlich die Transitivität, in ihre Analyse ein.

13 In ihrem Beitrag „Neuhochdeutsche und neuniederländische Bildungen mit dem Präfix ver-“ aus dem Jahre 1976 beschäftigt sich Tellenbach intensiv mit den Bedeutungen des Präfixes ver-, die sie mithilfe von elf sogenannter „,semantischer Nischen“, d. h. semantischer Verschiedenartigkeit, untersucht, dabei aber auf Schwierigkeiten stößt, die sie dazu bewegten, die ver-Verben als problematisch in ihrer Einordnung zu bezeichnen.

14 In „Wortbildung der deutschen Gegenwartssprache“ unterscheiden Fleischer, \& Barz (1983, 1995) drei Bedeutungsgruppen von ver-Verben - die erste nennen sie ,perfektive“, die zweite „modale“ und die dritte Gruppe ,intensive“ ver-Verben.

15 Mungans Arbeit „Die semantische Interaktion zwischen dem präfigierenden Verbzusatz und dem Simplex bei deutschen Partikel- und Präfixverben“ (1986) ist nicht nur für die Untersuchung des Präfixes ver- wichtig - hier finden wir, nebst einem guten Überblick über die Forschung der Präfixe, auch eine sehr detaillierte semantische Beschreibung deutscher Präfixe. Er plädiert für eine Analyse der ver-Verben in diachronem und nicht nur in synchronem Hinblick, da die Bedeutung des Präfixes ver-erst durch die Erschließung seiner Entstehungsgeschichte verstanden werden kann.

16 Zu den echten Präfixen zählen, neben ver-, gleichfalls be-, ent-, er-, ge- und zer- (vgl. Altmann, \& Kemmerling, 2005: 64; Fleischer, \& Barz, 1995: 37). 
1. Modifizierung, ${ }^{17}$
2. Vollständigkeit,
3. Präzisierung,
4. Sprachökonomie ${ }^{19}$ und
5. Flexibilität.

5.3 Das verbale Präfix ver- kann oft auch transitivierend wirken (vgl. Altmann, \& Kimmerling, 2005: 74). ver- kann also die Transitivität des Verbs beeinflussen bzw. die Transitivität kann durch die Präfigierung ausgedrückt werden, wie schon Kühnhold bemerkte (vgl. Kühnhold, 1976). Auf diese Weise wird das Grundwort, d. i. das Grundverb, welches ein Dativobjekt besitzt, zum präfigierten Verb mit Akkusativobjekt: jmdm. folgen -jdn. verfolgen (vgl. Berthele, 2006: 47). Im vorliegenden Beitrag werden weder die morphologischen noch die syntaktischen Merkmale in die Analyse miteinbezogen, einerseits, um den in den älteren Forschungen vernachlässigten semantischen Merkmalen mehr Aufmerksamkeit, die ihnen zweifelsohne gebührt, schenken zu können, andererseits aber auch, um den Rahmen dieses Beitrags nicht zu sprengen.

\section{Zur Analyse}

6.1 Bei der Analyse des aus dem Korpus gewonnenen Materials wurden bestimmte Kriterien bzw. Richtlinien zur Einstufung der erhaltenen ver-Verben zusammengestellt. Diese Richtlinien basieren auf semantischen Kriterien. Es wurde auf eine verfeinerte Gruppeneinteilung verzichtet, da dies vielmehr zu Verwirrungen geführt hätte, was im Gegensatz zum verfolgten Ziel dieses Beitrags stehen würde. Indem die repräsentativen semantischen Richtlinien zu Rate gezogen wurden, konnten auf diese Weise insgesamt neun Gruppen der ver-Verben zusammengestellt werden: ${ }^{20}$

1. Gruppe: hierzu gehören all jene ver-Verben, die das Aufbrauchen oder Beseitigen einer Sache kennzeichnen: z. B. veressen, vertreiben usw.

Gruppe: in dieser Gruppe befinden sich ver-Verben, die ein Zugrundegehen oder Fort- bzw. Weggehen zum Ausdruck bringen: verklingen, verreisen usw.

2. Gruppe: diese ver-Verben beschreiben, dass eine Person etwas falsch macht, dass sie fehlgeht oder irregeleitet wird; gleichzeitig können hierzu auch jene

Präfixe, und somit auch das Präfix ver-, modifizieren die Grundbedeutung eines Verbs und tragen somit zur Wortschatzerweiterung bei.

18 Durch das Präfix ver- wird „die vollständige Durchführung einer Handlung“ (Fleischer, \& Barz, 1995: 325) bzw. die „,verkehrte Durchführung einer Handlung“ markieret (Altmann, \& Kimmerling, 2005: 74).

19 Bei Mungan (1986) wird als eine wichtige Leistung des Präfixes ver- die Präzisierung betont und damit verbunden die Sprachökonomie: Lange umschreibende Sätze bzw. Phrasen werden auf diese Weise vermieden (z. B. Er ist gestorben, weil er nichts mehr zum Essen hatte. $\rightarrow$ Er ist verhungert.).

20 Zur Kennzeichnung der angeführten Gruppen wurde teils auf schon bestehende Einteilungen der Funktionen von ver- zurückgegriffen - etwa von Kühnhold (1973), Tellenbach (1976), Mungan (1986), Pfeifer (1989), Fleischer, \& Barz (1983, 1995), Donalies (2005), Duden (2005) - teils wurden aber auch neue, präziser definierte Gruppen gebildet. 
ver-Verben gerechnet werden, die eine Art der Negation darstellen: z. B. verrechnen, verwechseln usw.

3. Gruppe: hierzu gehören ver-Verben, die eine Verbindung, im weitesten Sinne, kennzeichnen: z. B. verheiraten, versammeln usw.

4. Gruppe: das sind jene ver-Verben, die einen resultativen Sinn ausdrücken: $\mathrm{z}$. B. verbluten, verblühen usw.

5. Gruppe: in dieser Gruppe sind ver-Verben der Intensivierung bzw. Verstärkung zu finden: z. B. verschließen usw.

6. Gruppe: hier befinden sich ver-Verben, die ausdrücken, dass die Tätigkeit, die das Verb beschreibt, im übertriebenen Maße vollzogen wird, oder, wie es Donalies erklärt, dass es „,durch unsachgemäße Durchführung der Tätigkeit“ zu einer Art Beschädigung kommt (Donalies, 2005: 118): z. B. verbacken usw.

7. Gruppe: diese ver-Verben beschreiben, dass eine Tätigkeit längere Zeit andauert: z. B. sich verreden usw.

8. Gruppe: in diese Gruppe fallen alle ver-Verben, die zu keiner der oben genannten Gruppe zu rechnen sind.

6.1.1 Die erste Gruppe bilden jene ver-Verben, die das Aufbrauchen oder Beseitigen einer Sache kennzeichnen. ${ }^{21}$ Im Korpus konnten insgesamt 31 solcher $v e r$-Verben exzerpiert werden. Es handelt sich um folgende Verben:

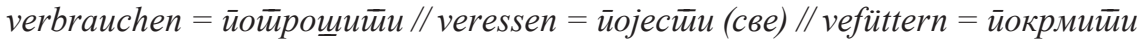

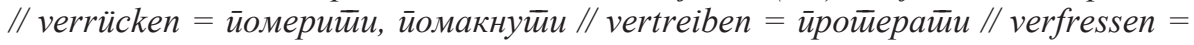

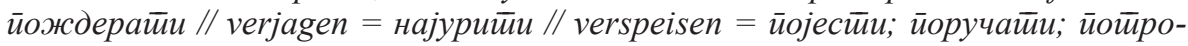

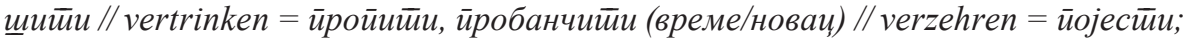

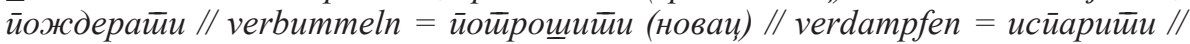

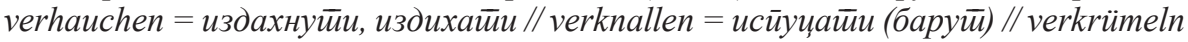

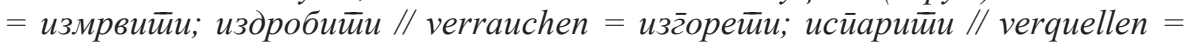

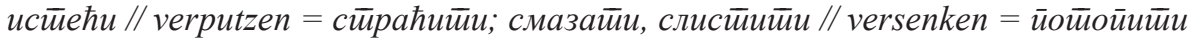

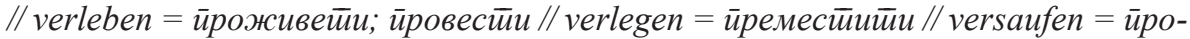
$\bar{u} и \bar{u} и / /$ verstellen $=\overline{и о м а к н у и ̆ и ~}$

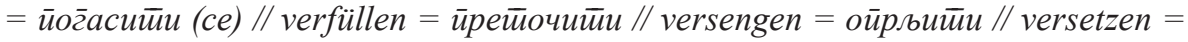

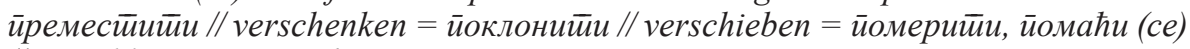
// verschlemmen $=\bar{u}$ роћердайu

Es zeigt sich, dass die meisten ver-Verben dieser Gruppe mit dem Präfix $\bar{u} o-$, welches im Serbischen eines der produktivsten ist, übersetzt worden sind. Im Serbischen drücken die Verben mit dem Präfix $\bar{u} o$ - meist aus, dass die Handlung zu Ende geführt wurde (vgl. Stevanović, 1964: 460; Rečnik srpskoga jezika, 2007: 937). Ebenfalls drücken sie aus, dass eine Handlung auf der Oberfläche eines Gegenstandes durchgeführt wird, aber auch, dass jemand bzw. etwas mit dem, das das Grundwort bedeutet, versorgt wird - etwa йойращийи (,bestauben') (vgl. Stevanović, 1964: 460). ${ }^{22}$

$21 \quad$ Interessant ist, dass Stiebels (1996) der Meinung ist, dass die Bedeutung des Aufbrauchens (sie nennt das Konsumieren) die eigentliche Bedeutung des Präfixes ver- sei (vgl. Stiebels, 1996: 136-138).

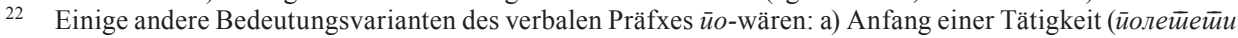
- , anfangen zu fliegen'), b) eine Tätigkeit wird nur teilweise und kurzweilig ausgeführt ( $\overline{\text { ü }} p с к а \bar{u} и-$ 
6.1.2 Die zweite Gruppe beinhaltet jene ver-Verben, die ein Zugrundegehen oder Fort- bzw. Weggehen zum Ausdruck bringen. Im Korpus wurden folgende ver-Verben, 33 an der Zahl, die in diese Gruppe gehören, gefunden:

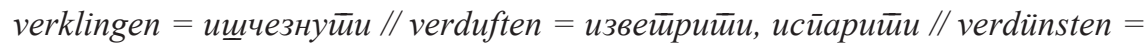

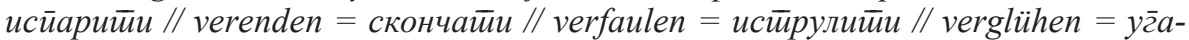

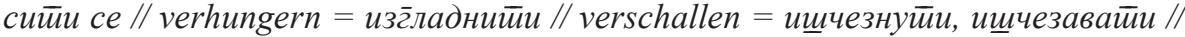

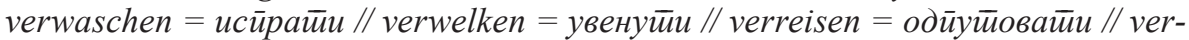

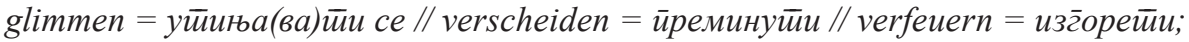

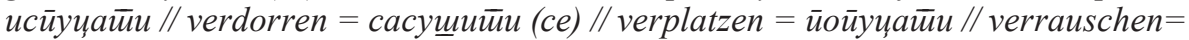

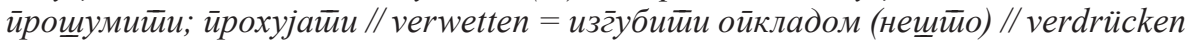
$($ sich $)=\overline{и о в у ћ и ~(c e) ~ / / ~ v e r h a l l e n ~=~ и щ ч е з н у и ̆ и ; ~ и з г ̄ у б и т и и ~ с е ~ / / ~ v e r h e t z e n ~=~ и ̆ р о г ̄ o-~}$

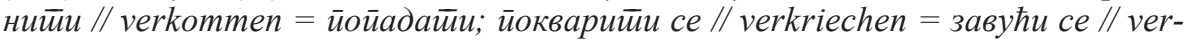

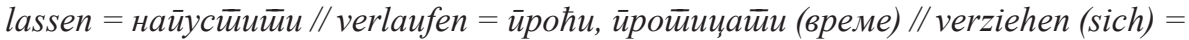

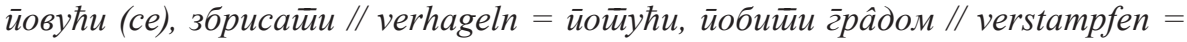

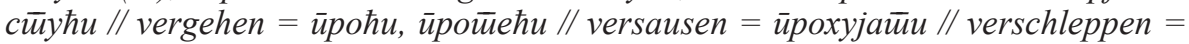

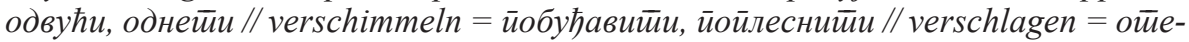

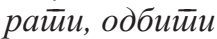

Die ver-Verben dieser Gruppe können ins Serbische mit Verben mit dem Präfix из- bzw. $u c$ - übersetzt werden. Verben mit dem Präfix $и з$ - haben mehrere Bedeutungen, laut Stevanović (1964: 456) sind es sechs, dem Wörterbuch Rečnik srpskoga jezika (2007: 446) nach sind es neun. ${ }^{23}$ Hier kommt vor allem die Bedeutung im Sinne einer Vollendung der Handlung in Frage.

6.1.3 In der dritten Gruppe befinden sich alle ver-Verben, die eine Art der Negation darstellen und besagen, dass eine Person etwas falsch macht, dass sie fehlgeht oder irregeleitet wird. Folgende 79 Verben können zu dieser Gruppe gerechnet werden:

verbauen $=$ зазидайи $/ /$ verbieten $=$ забранийи $/ /$ vereitern $($ sich $)=$ заг̈нојийи

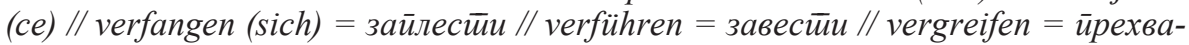

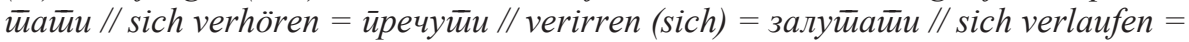

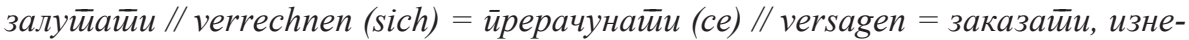

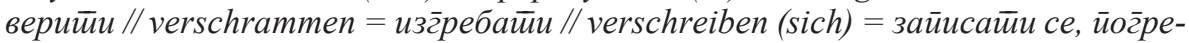
щийи у иилсању // versprechen (sich) = зайричайи се, найравийи лайсус // ver-

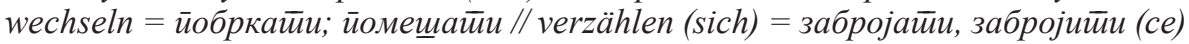

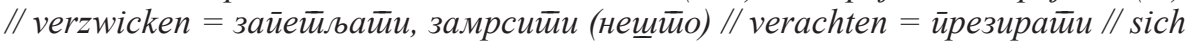

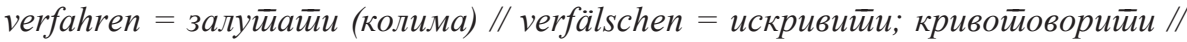

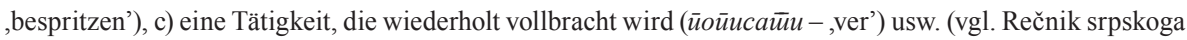
jezika, 2007: 937).

23 Der Vollständigkeit halber muss angeführt werden, welche Bedeutungsvarianten das serbische Präfix из- bei Verben aufweisen kann: a) die Bewegung aus dem Inneren von etwas bzw. das Verlassen eines

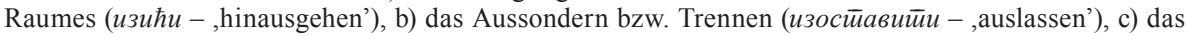
Erlangen oder Erreichen von etwas (изнудийи - ,erzwingen'), d) das Bewegen nach oben (исиеиеии се ,hinaufsteigen'), e) das Vollenden einer Handlung bzw. das Ende derselben (изг̄ope $\bar{u} u$-,verbrennen'), f) das Vollenden einer Handlung bis zur Zufriedenstellung (исйавайи се -, sich ausschlafen'), g) das Vollenden einer Handlung auf mehrere Objekte (израздвајат̄ - , alles vollständig trennen') und zuguterletzt h) die Ausbreitung der Handlung auf den ganzen Gegenstand (измазайи -,verschmieren') (vgl. Rečnik srpskoga jezika, 2007: 446). 


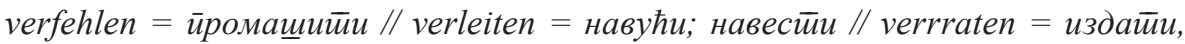

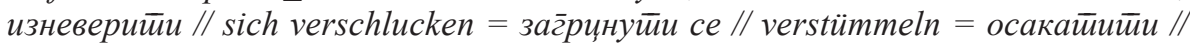

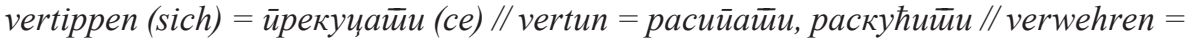

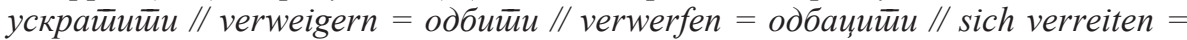

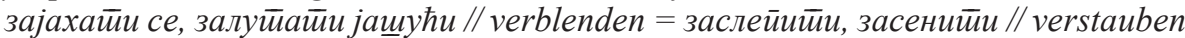

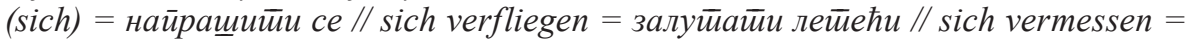

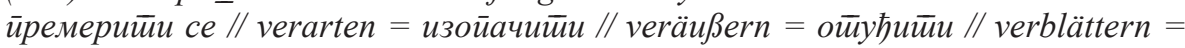

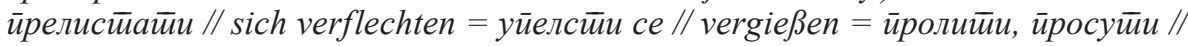

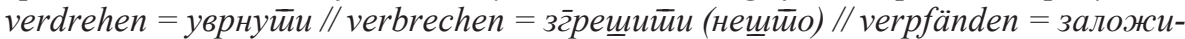

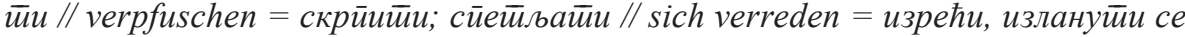

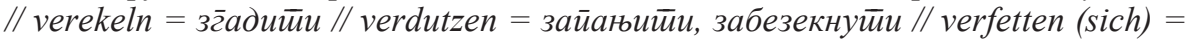

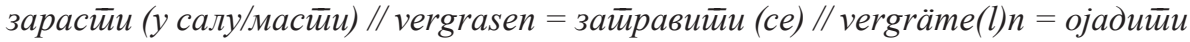

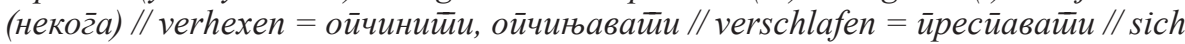

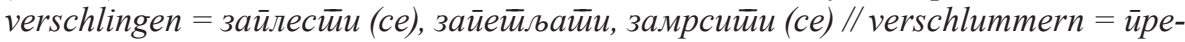

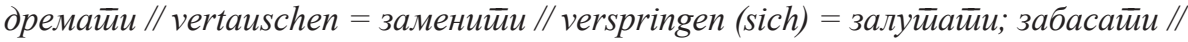

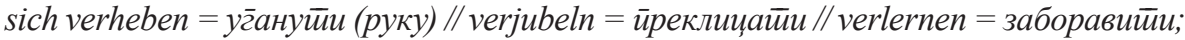

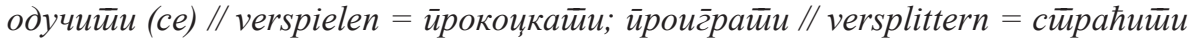

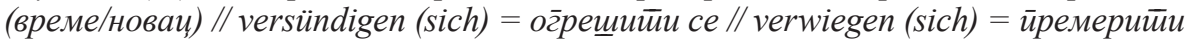

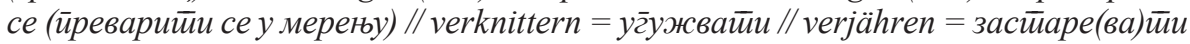

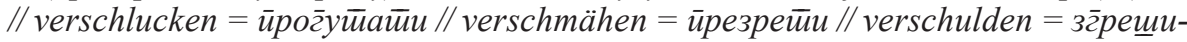

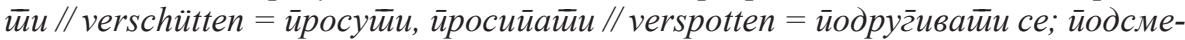

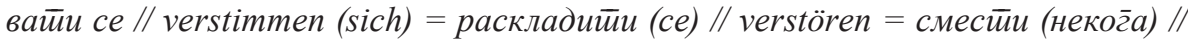

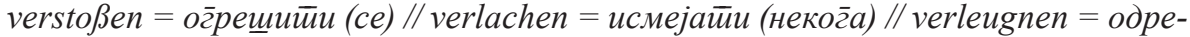

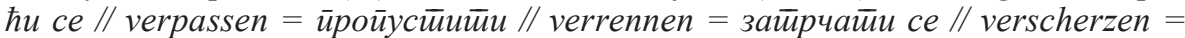

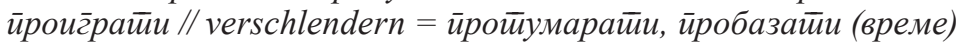

Es konnte festgestellt werden, dass die Mehrzahl der ver-Verben der dritten Gruppe mit dem Präfix $3 a$ - ins Serbische übersetzt werden. An dieser Stelle sei betont, dass das serbische Präfix $3 a-$, so, wie es im Korpus verwendet wird, dazu dient, dass die damit verbundenen Verben das Weiterführen eines Prozesses zum Ausdruck bringen. Sie drücken weiterhin aus, dass dieses weitere Durchführen des Prozesses in eine falsche, ungewollte Richtung geht (vgl. Stevanović, 1964: 455). ${ }^{24}$ So wird im Serbischen das Verb закосит̄u (ce) (,sich vermähen') verwendet, wenn zum Ausdruck gebracht werden soll, dass jemand beim Rasenmähen zum Beispiel auf den Rasen des Nachbars übergegangen ist und dort, ungewollt, den (falschen) Prozess weitergeführt hat (vgl. ebd.). In diesem Sinne können auch die im Korpus gefundenen ver-Verben verstanden werden, etwa sich verrechnen, sich verlesen, sich verzählen usw.

24 Das Präfix $3 a$ - kann auch andere Bedeutungen haben - es sind insgesamt 19 zu unterscheiden; aus Platzgründen werden hier nur einige dieser Bedeutungsvarianten angeführt: a) der Anfang einer Handlung oder eines Zustandes (зайевайu - ,anfangen zu singen'), b) die teilweise Vollendung einer Handlung

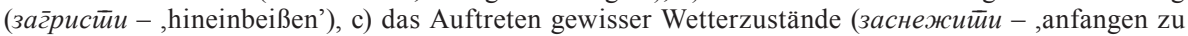
schneien'), d) das Umdrehen oder Entfernen eines Teils von etwas (заврнуйи - ,umschlagen'), e) eine längere Beschäftigung mit einer Tätigkeit (зайричайи се - ,sich verreden'), f) das Verbinden an etwas

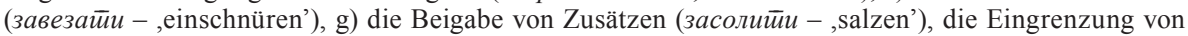
etwas (зазидат̄u - ,einmauern') usw. (vgl. Rečnik srpskoga jezika, 2007: 378). 
6.1.4 Die vierte Gruppe beinhaltet jene ver-Verben, die eine Verbindung, im weitesten Sinne, kennzeichnen. Im Korpus konnten folgende 23 ver-Verben, die in diese Gruppe gehören, exzerpiert werden:

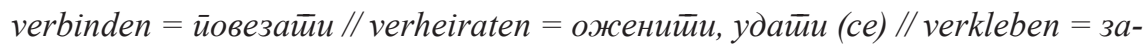

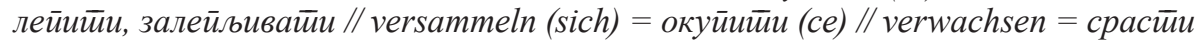

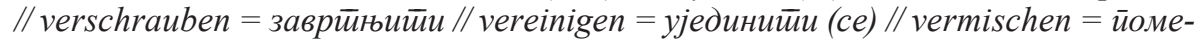

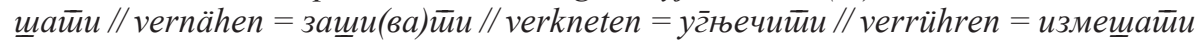
// verstricken (sich) = уйлестии (ce) // verweben (sich) = исирейлесіии (се) // ver-

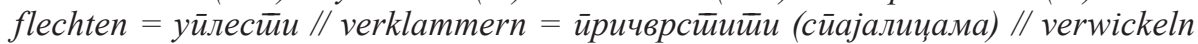

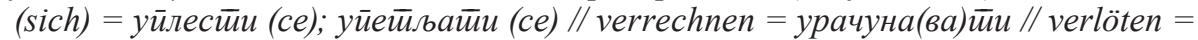

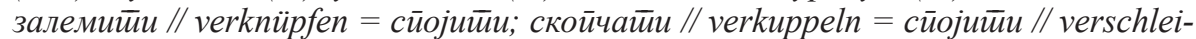

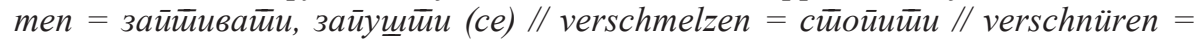
увезивайи // verschwören (sich) = заверийи се //

Die meisten der angeführten ver-Verben der vierten Gruppe haben im Serbischen Entsprechungen, die mit dem Präfix $y$ - bzw. den $y$-Verben gebildet werden. Die serbischen $y$-Verben bezeichnen, laut dem Wörterbuch Rečnik srpskoga jezika (2007), v. a. das Eindringen in das Innere von etwas (улетеией -, hineinfliegen'), aber auch die Vollendung der Tätigkeit, die im Verb ausgedrückt wird

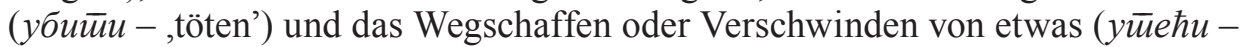
,davonkommen'). Die Bedeutung, die hier angedeutet wird, nämlich eine Verbindung, wird mit keinem Wort erwähnt, was doch überraschend ist.

6.1.5 Die ver-Verben der fünften Gruppe drücken einen resultativen Sinn aus. Insgesamt konnten 98 ver-Verben, die hierzu gehören, herausgesucht werden. Das sind folgende ver-Verben:

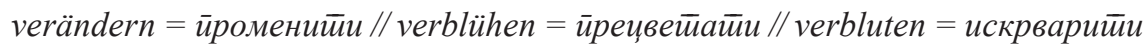

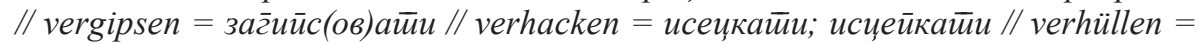

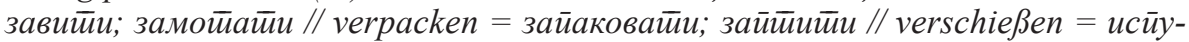

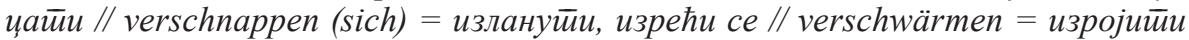

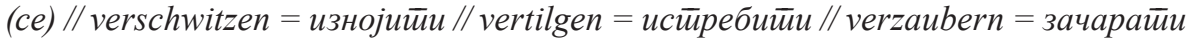

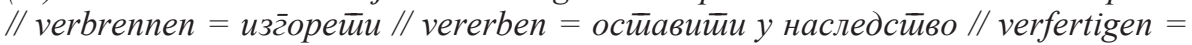

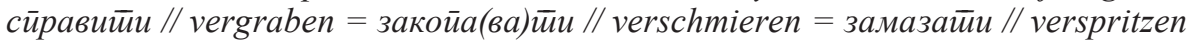

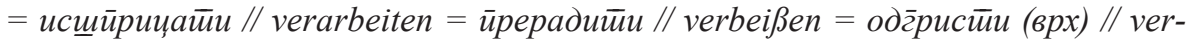

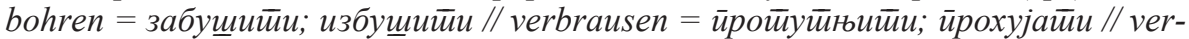

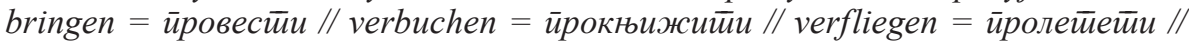

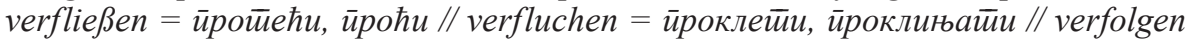

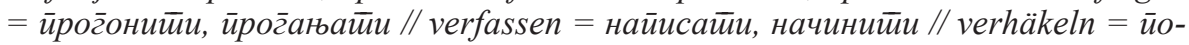

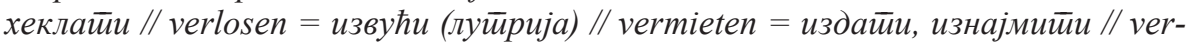

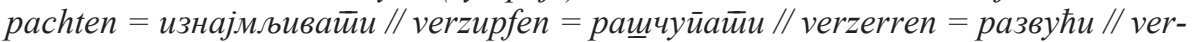
mаиегn = зазидайи // vermerken = забележийи (себи нешимо) // vernebeln $=$ за-

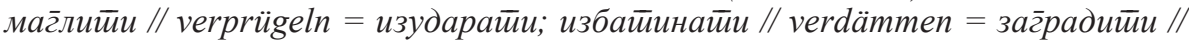

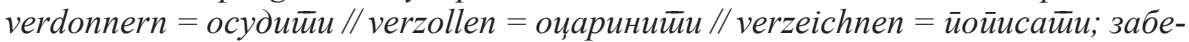

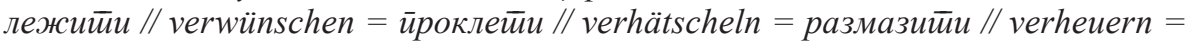

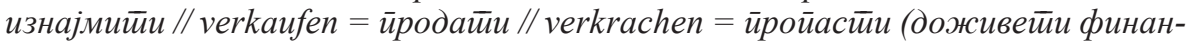

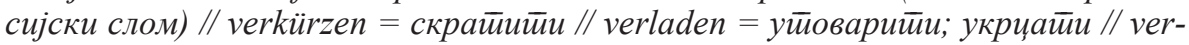

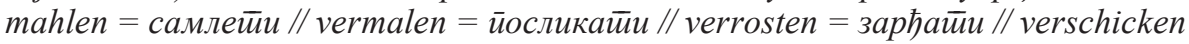




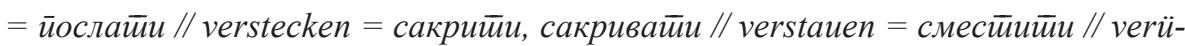

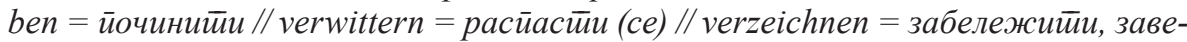

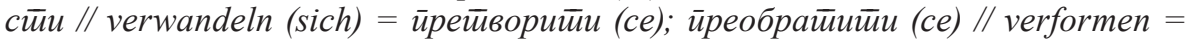

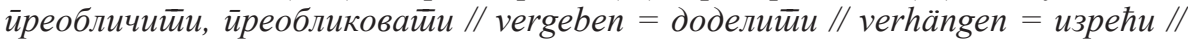

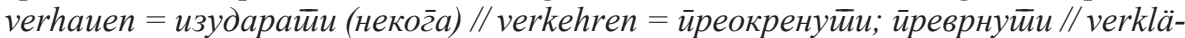

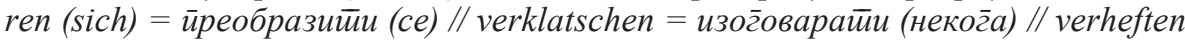

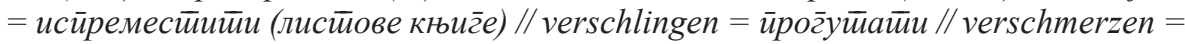

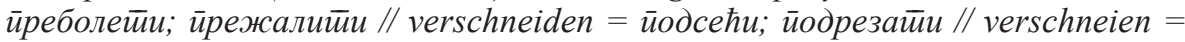

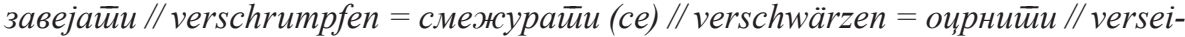

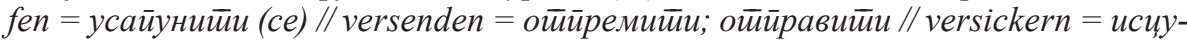

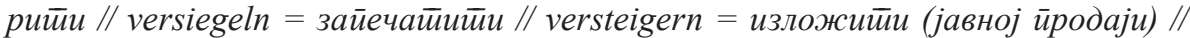

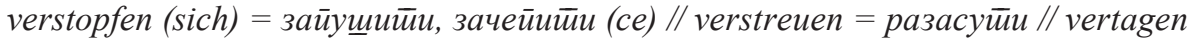

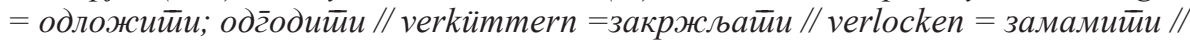

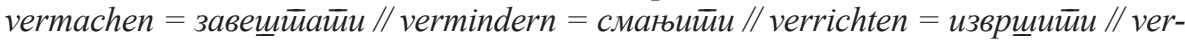

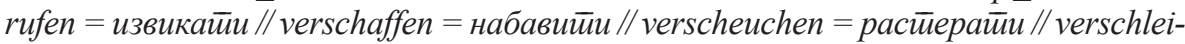

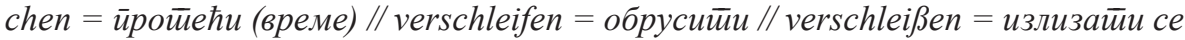

Bemerkbar ist, dass ein Großteil dieser ver-Verben mit dem Präfix из- bzw. $u c$ - ins Serbische übersetzt wurde. Serbische Verben mit dem Präfix $и з-$ drücken - wie schon erwähnt - aus, dass eine Handlung vollkommen ausgeführt wird bzw. wurde (vgl. Stevanović, 1964: 256; Rečnik srpskoga jezika, 2007: 446). Demnach stimmen sie in ihrer Bedeutung mit jener, die auch bei der zweiten Gruppe anzutreffen war, überein. ${ }^{25}$

6.1.6 Die sechste Gruppe stellt jene ver-Verben dar, die eine Intensivierung bzw. Verstärkung ausdrücken. Folgende ver-Verben, die aus dem Korpus herausgesucht wurden - ihrer 53 an der Zahl, sind zu dieser Gruppe zu rechnen:

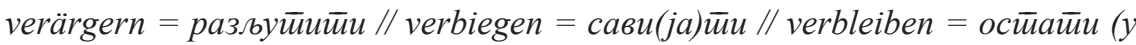

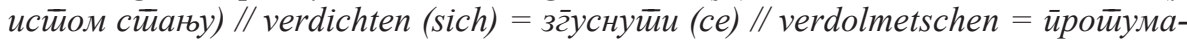

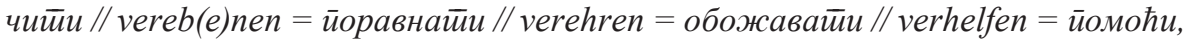

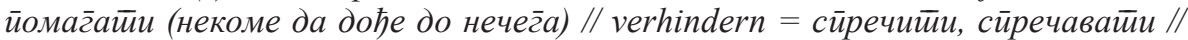

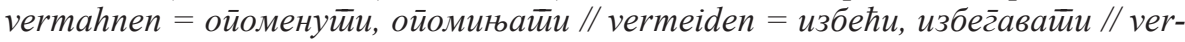

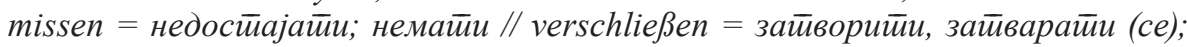

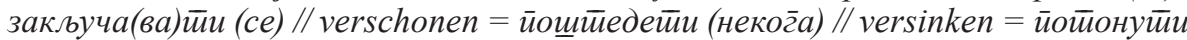

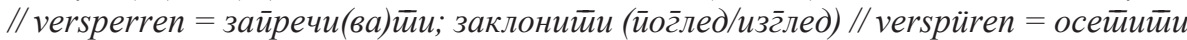

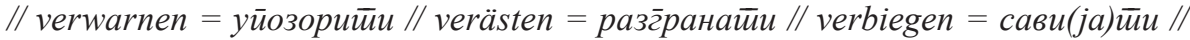

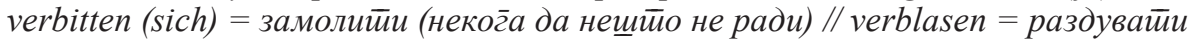

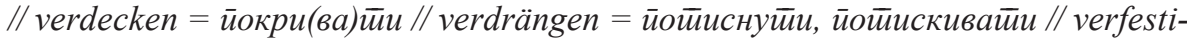

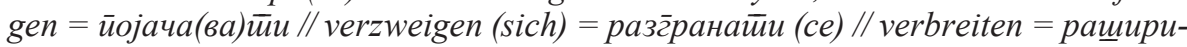

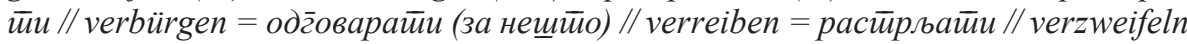

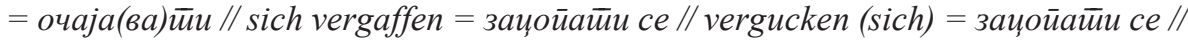

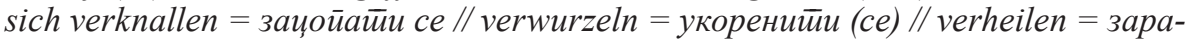

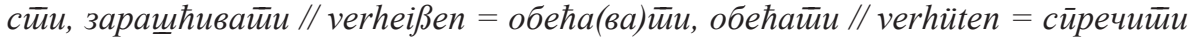

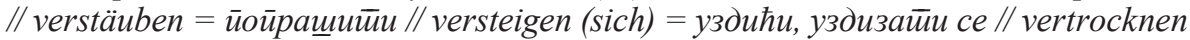

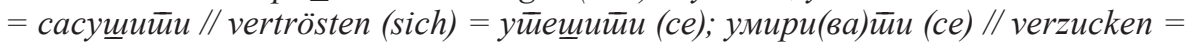

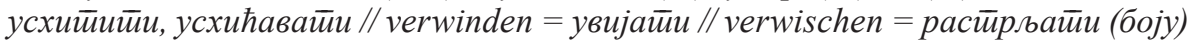




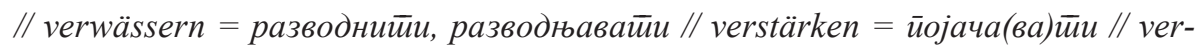

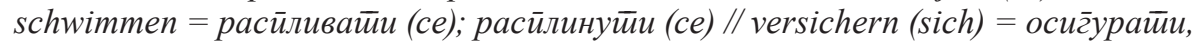

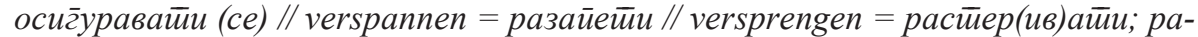

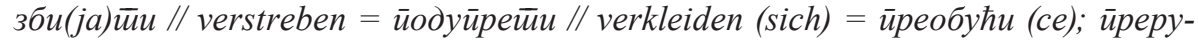

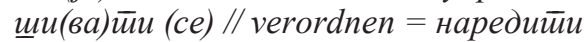

Hier treten in Form der serbischen Entsprechungen einige paз-Verben auf. Das serbische Präfix раз- bezeichnet v. a. eine Teilung (развестии се - ,sich scheiden lassen'), Erweiterung oder Vergrößerung (ㅆирийи се - , sich ausbreiten'). Daneben wird aber auch die hier vorwiegende Bedeutung des Präfixes paз- verwendet: Es handelt sich um die Verstärkung der Intensität eines Prozesses oder

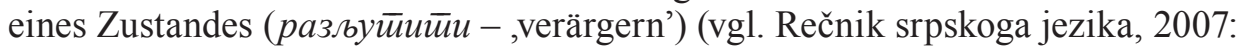
1106).

6.1.7 In der siebten Gruppe befinden sich 8 ver-Verben, die das Übertreiben in einer Tätigkeit beschreiben, wodurch es zu einer Art Beschädigung kommt. Dazu gehören folgende ver-Verben:

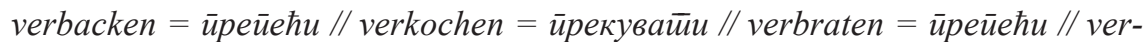

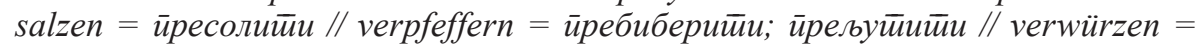

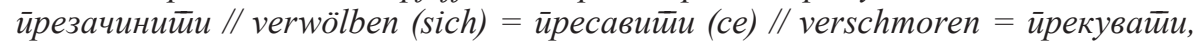
иреиржитии

In dieser vom Umfang her kleinsten Gruppe sieht man, dass alle diese ver-Verben mit dem Präfix ūpe- ins Serbische übersetzt wurden. Das Präfix ūpe- ist bei serbischen Verben sehr produktiv - Verben mit diesem Präfix beziehen sich, u. a., auf das Maß, in dem eine Tätigkeit vollzogen wird. ${ }^{26}$ Bei den Verben wie zum

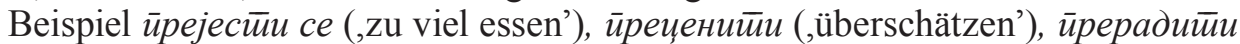
се (,sich überarbeiten'), ирреморийи се (,sich übermüden'), ирреиуунитии (,überfüllen') usw. handelt es sich somit um Verben, die zeigen, dass etwas im übertriebenen Maße gemacht wurde (vgl. Stevanović, 1964: 462). Interessant ist, dass diese Verben im Deutschen vor allem mit Verben, die die Präfixe über- und um- haben, übersetzt werden würden.

6.1.8 In der achten Gruppe befinden sich alle ver-Verben, die eine längere Beschäftigung mit der im Verb ausgedrückten Tätigkeit beschreiben. Es handelt sich um folgende 36 ver-Verben:

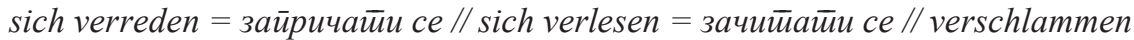

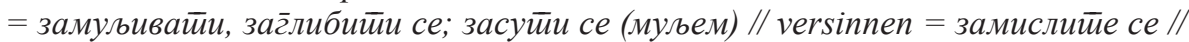
(sich) vertelefonieren $=/ /$ versegeln $=$ заједрилийи //vergähnеn $=$ йрозевайи $(\overline{u ̈ р о в е-~}$

26 Das serbische Präfix üpe-hat in Kombination mit Verben mehrere Bedeutungen und Bedetungsvarianten, in manchen Quellen (etwa im Rečnik srpskoga jezika, 2007) ist die Rede von sogar acht Bedeutungen: So kann ein üpe-Verb zum Ausdruck bringen a) die Richtung der Handlung bzw. die Bewegung aus einem Ort zum anderen u. Ä. ausdrücken (wie z. B. bei йреселийи се - umziehen'), b) die Veränderung der Lage (etwa bei йреврнуйи - umdrehen'), c) die Wiederholung einer Handlung (z. B. иррерадий ,umarbeiten'), d) die Übertreibung einer Handlung/Tätigkeit (z. B. ūpeūeћu -,verbacken'), e) die Zweiteilung von etwas (z. B. йpeceћu - zerschneiden'), f) das Ausfüllen der Handlung (etwa йреноћийu - ,übernachten'), g) die Kurzweiligkeit einer Handlung (z. B. йредахнуйu - ,verschnaufen') und h) das Ende einer Handlung (z. В. ирреболейи - überwinden) (vgl. Rečnik srpskog jezika, 2007: 1001). 
сӣи у зевању) // vertelefonieren = зайричайи се (ирреко йелефона) // sich verspielen

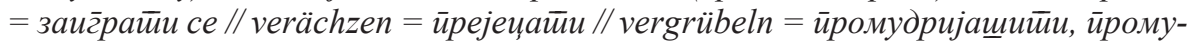

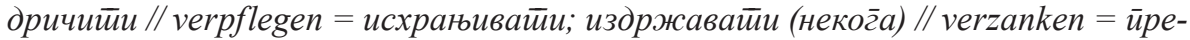

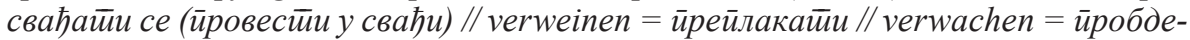

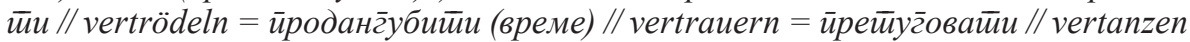

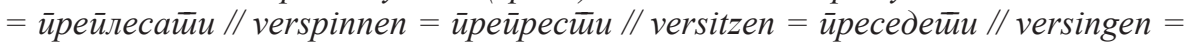

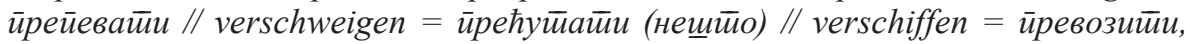

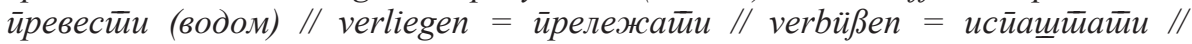

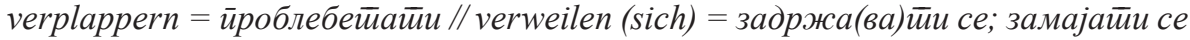

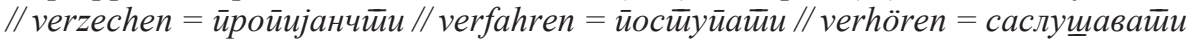

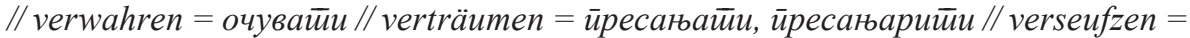

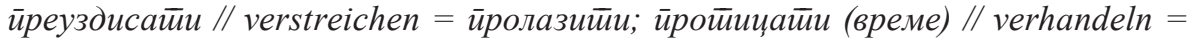

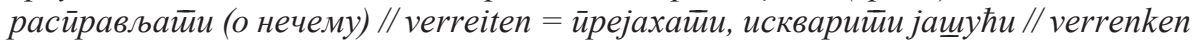

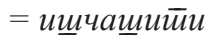

Die ver-Verben dieser Gruppe haben oft serbische Entsprechungen, die das Präfix üpe-aufweisen, welches schon bei der vorigen, siebten Gruppe beschrieben wurde. Interessanterweise wird weder bei Stevanović noch im Wörterbuch Rečnik srpskoga jezika dem serbischen Präfix üpe- die Möglichkeit eingeräumt, in Kombination mit einem Verb die längere Beschäftigung mit einer Tätigkeit auszudrücken, obwohl dies schon anhand weniger der hier angeführten Beispiele nachvollziehbar wird. ${ }^{27}$ Auch hier, wie bei der dritten Gruppe der ver-Verben, konnte festgestellt werden, dass viele dieser ver-Verben als Verben mit dem Präfix $3 a$ - im Serbischen erscheinen. Hier ist aber die Bedeutung eine andere: Das Präfix $3 a$ - wird hier verwendet, um die länger andauernde Beschäftigung mit einer Tätigkeit auszudrücken (vgl. Fußnote 13, e).

Das serbische Präfix üpo- erscheint sowohl bei den Entsprechungen der ver-Verben dieser, aber auch der anderen Gruppen sporadisch, weshalb eine Beschreibung derselben erforderlich erschient. Das Präfix üpo-kann nämlich bei den serbischen Verben fünf Bedeutungsvarianten aufweisen: 1. eine vollendete Handlung - a) infolgederer es zum Durchbrechen bzw. Durchgehen kommt (üpoбит̄ $u$ - ,durchstechen'), b) die in ihrer Dauer kurz ist und sich in geringem Maße

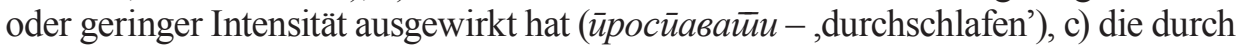
langwierige Arbeit und sorgfältige Untersuchung gekennzeichnet ist ( $\bar{p} о с \bar{u} y \partial u$ pa $\bar{u} u$-,durchstudieren'), d) die eine Art des Nebeneinanderbewegens kennzeichnet (иролетиети - , verfliegen') und 2. den Anfang eines Handlungsvollzugs (üрог̄oворит̄u - , anfangen zu reden') (vgl. Rečnik srpskoga jezika, 2007: 1054).

6.1.9 Die neunte und letzte Gruppe stellt alle ver-Verben dar, die zu keiner der acht vorangehenden Gruppen zu rechnen sind. Das sind folgende 30 ver-Verben:

verantworten = одговарати (за нешто) // verlieben (sich) = заљубити ce // verdanken = дуговати; захваљивати // verdienen = зарадити, зарађивати // verloben $($ sich) =

27 Man denke nur an das Beispiel, das den serbischen Alltag, bedauernswerterweise, treffend beschreibt: „Дуго сам чекала да дођем на ред код лекара - иреседела сам у чекаоници готово цео дан!“ (,Ich habe lange gewartet, um beim Arzt an die Reihe zu kommen - fast den ganzen Tag habe ich im Warteraum versessen!'). 
заручити се // verwenden = употребити, употребљавати // verstehen = разумети // versprechen = обећа(ва)ти // sich verhalten $=$ понашати ce $/ /$ verzögern $=$ одгодити, одгађати; одуговлачити // verzimmern = подградити, подграђивати (дрветом) // verwerten = уновчити // versuchen = покуша(ва)ти // verhaften = ухапсити; затворити // versorgen = опскрбити // verfügen = располагати (нечим) $/ /$ vergelten = надокнадити (некоме нешто); наградити (услугу) // vergönnen = допустити, допуштати // vertrauen = (по)узда(ва)ти ce; // vertragen = поднети, подносити // versehen sich = снабдети, снабдевати се // verschreien = извикати // verschreiben = прописати // verleihen = поклонити, подарити; дати // vermögen = бити способан, кадар // vernehmen = опазити // verneigen (sich) = поклонити ce // verpflanzen = пресадити // verpumpen = позајмити // vertreten = заступати; заменити

\section{Auswertung}

7.1 Die Analyse des Korpus hat gezeigt, dass das deutsche verbale Präfix ver- in insgesamt 15 unterschiedlichen serbischen Präfixen seine Entsprechungen fand. ${ }^{28}$ Den jeweiligen Präfixen nach sieht die Verteilung wie folgt aus: 66 Mal mit

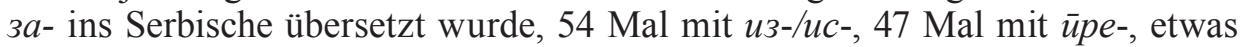
weniger, nämlich $44 \mathrm{Mal}$ mit $\bar{u} o-$, $39 \mathrm{Mal}$ mit $\bar{u} p o-, 36 \mathrm{Mal}$ mit $c-/ c a-/ 3-, 26 \mathrm{Mal}$ mit $y$-, 23 Mal mit раз-/рас-, 25 Mal mit o-/oб-/oи-, 8 Mal mit на-, 12 Mal mit $o \partial-/ o \bar{u}$-, 5 Mal mit $\bar{u} o \partial-, 2$ Mal mit $\partial o-$, nur 1 Mal mit yz- und ebenso nur $1 \mathrm{Mal}$ mit üpu-. Graphisch und damit leichter überblickbar könnte das Vorangesagte folgendermaßen dargestellt werden:

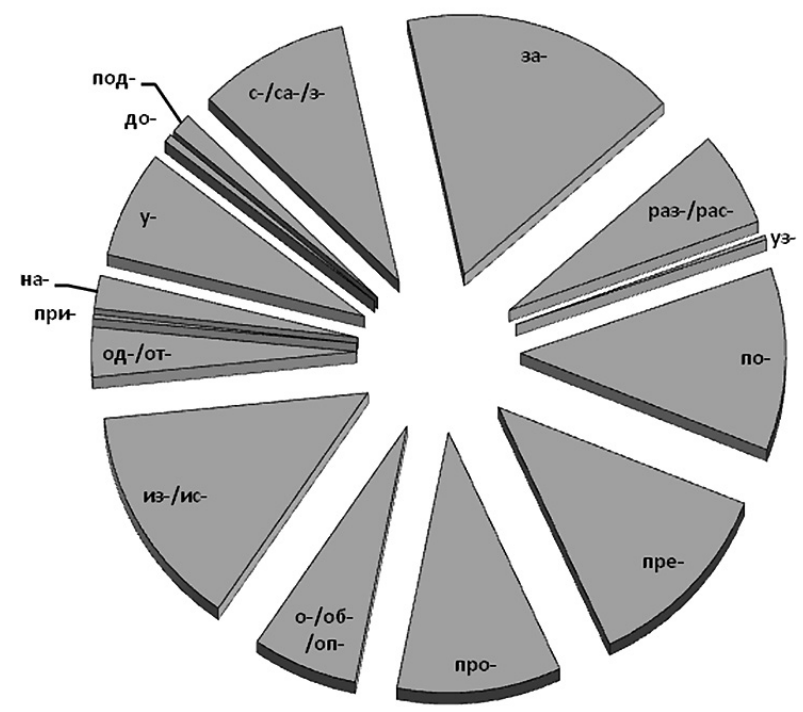

Graphik 1: Verteilung der serbischen Entsprechungen der ver-Verben

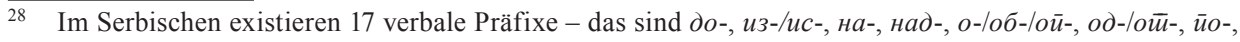
йод-, йpe-, йpu-, йpo-, pas-/pac-, c-/ca-/3-, y-, y3-, за- (vgl. Klajn, 2002). 
7.2 Wie man sieht, haben die meisten der deutschen ver-Verben ihre Entsprechungen in serbischen $3 a$-Verben. Zahlreich vertreten sind auch die serbischen Entsprechungen, welche mit den Präfixen $u$ з- $/ u c-, \bar{u} o-$, üpe-, üpo- und $c$-/ca-/3- gebildet werden. Zwanzig Prozent aller aus dem Korpus exzerpierten ver-Verben haben Entsprechungen, die in den serbischen $y$-, раз-/pac bzw. o-/об-/oü-Verben zu finden sind. Eine relativ kleine Gruppe der ver-Verben hat ihre Entsprechungen in serbischen $о \partial-/ o \bar{u}$-, $H a$-und $\bar{u} о \partial$-Verben, während der Prozentanteil der serbischen Entsprechungen, die mit den Präfixen $\partial o-, y z-$ und $\bar{u} p u$-realisiert werden nur $0,01 \%$ ist.

7.3 Es wurden insgesamt neun semantische Gruppen der ver-Verben gebildet. Es hat sich gezeigt, dass diese Gruppen dem Umfang nach nicht gerade gleichmäßig sind. Die meisten aus dem Korpus exzerpierten ver-Verben befinden sich in der fünften Gruppe (98), die wenigsten in der siebten Gruppe (nur acht). Graphisch ließe sich das deutlicher präsentieren:

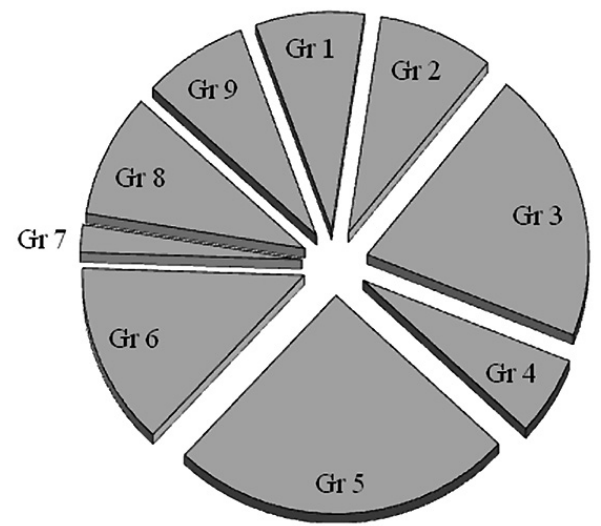

Graphik 2: Verteilung der ver-Verben nach semantischen Gruppen

7.4 Bezüglich einiger ver-Verben, die in diesem Beitrag angeführt wurden, muss hervorgehoben werden, dass bei andersweitiger Analyse die vorgenommene Einordnung in die Gruppen auch anders ausfallen könnte, so etwa beim Verb verfälschen. Dieses ver-Verb kann sowohl als Verb der sechsten Gruppe als auch der dritten Gruppe betrachtet werden - es drückt einerseits etwas, das negativ ist aus, andererseits aber auch, dass es zur Intensivierung der im Grundwort ausgedrückten Tätigkeit kommt. Auch beim Verb versinken könnte außer der Intensivierung von sinken sowohl etwas Negatives als auch die Vollendung der im Verb ausgedrückten Handlung hervorgehoben werden. ${ }^{29}$

7.5 Es stellte sich heraus, dass es auch ver-Verben gibt, deren Bedeutung nicht zu bestimmen ist, da diese Verben im Hinblick auf das dazugehörige Präfix un-

Denn, für denjenigen, der versunken ist, wie es etwa beim Schiff Titanic der Fall war, ist jegliche Handlung abgeschlossen! 
durchsichtig bzw. unmotiviert sind. Das heißt, dass die eigentliche Bedeutung des Verbs (z. B. verantworten) nicht aus der Bedetung des Grundwortes (antworten) erschlossen werden kann. Interessant ist, dass es im Korpus bei Weitem mehr ver-Verben gibt, die ins Serbische ebenfalls mit Präfixverben übersetzt werden können, als ver-Verben, die nur umschreibend zu übersetzen sind. Die Zahl solcher Verben hält sich in Grenzen - es wurden nur zwei ver-Verb, nämlich vermögen (,бити способан, кадар') und vermissen (,недостајати’) exzerpiert.

\section{Schlussfolgerungen}

8.1 Aufgrund der durchgeführten Analyse konnte festgestellt werden, welches serbische Präfix die am meisten gebrauchte Entsprechung zum deutschen verbalen Präfix ver- bildet. Ebenfalls konnten die untersuchten ver-Verben nach ihrer semantischen Leistung klassifiziert werden, wodurch auf die Ähnlichkeiten und auf die Unterschiede zwischen dem Deutschen und dem Serbischen - bezüglich des untersuchten Phänomens - hingewiesen werden konnten. Demnach konnte es gezeigt werden, dass, dank der Kontrastierung dieser zwei Sprachen anhand der ver-Verben, trotz struktureller Unterschiede semantische Parallelen aufgestellt werden können.

8.2 Einem Vergleich, wie er in diesem Beitrag vorgenommen wurde, ist bis jetzt kaum Aufmerksamkeit geschenkt worden. Es existiert keine kontrastive deutsch-serbische Untersuchung zu dieser grammatischen Erscheinung. Das ist beinahe unfassbar, wenn man die alltäglichen Probleme eines jeden DaF-Lerners vor Augen hat. Für den DaF-Lerner ist es schwierig, alle Präfixverben zu lernen, da sie so konzipiert sind, dass sie über Semen verfügen, die im Grunde potentiell sind, was zur Mehrdeutigkeit bzw. Polysemie führt und unvermeidbar zu großen Verständnisschwierigkeiten. Die Autoren des vorliegenden Beitrags hoffen, mit ihrer Arbeit allen, die Deutsch als Fremdsprache lernen oder studieren, bei der Erweiterung ihres Wortschatzes behilflich sein zu können und ihrem Verständnis bei der Bedeutungsdifferenzierung zwischen den einzelnen Präfixverben beitragen zu dürfen.

\section{LITERATUR}

Altmann, H. \& Kemmerling, S. (2005). Wortbildung fürs Examen. Bd. 2. Göttingen: Vandehoeck \& Ruprecht.

Berthele, R. (2006). Ort und Weg: Die sprachliche Raumreferenz in Variäteten des Deutschen, Rätoromanischen und Französischen. Berlin: Walter de Gruyter Verlag.

Bogner, S. (2010). Abriss der Geschichte der deutschen Sprache und der historischen Grammatik. Bačka Topola: LaVik 92 Verlag.

Braune, W. (1952). Gotische Grammatik. Halle/Saale: Max Niemeyer Verlag.

Divković, M. (1900). Latinsko-hrvatski rječnik za škole (Reprint izdanje, 1987.) Zagreb: Naprijed. 
Donalies, E. (2005). Die Wortbildung des Deutschen: Ein Überblick (2., überarbeitete Auflage). Studien zur Deutschen Sprache, Forschungen des Instituts für Deutsche Sprache. Tübingen: Gunter Narr Verlag.

DUDEN. 2000. Das Große Deutsche Wörterbuch. Mannheim. (e-Wörterbuch)

DUDEN. 2005. Die Grammatik (7. Auflage). Mannheim.

Eichinger, W. (2000). Deutsche Wortbildung: eine Einführung. Tübingen: Niemeyer.

Eisenberg, P. (2004). Grundriss der Deutschen Grammatik. Bd. 1. Stuttgart/Weimar: Metzler.

Feist, S. (1923). Etymologisches Wörterbuch der Gotischen Sprache. Halle (Saale): Max Niemeyer Verlag.

Fleischer, W., \& Barz, I. (1983). Wortbildung der deutschen Gegenwartssprache. Tübingen: Niemeyer.

Fleischer, W., \& Barz, I. (1995). Wortbildung der deutschen Gegenwartssprache. Tübingen: Niemeyer.

Gorski, O., \& Majranić, N. (1976). Grčko-hrvatski ili srpski rječnik. Zagreb: Školska knjiga.

Hennig, B. (1993). Kleines Mittelhochdeutsches Wörterbuch. Tübingen: Max Niemeyer Verlag.

Hentschel, E., \& Weydt, H. (2003). Handbuch der deutschen Grammatik (3. Auflage). Berlin: Walter de Gruyter.

Klajn, I. (2002). Tvorba reči u savremenom srpskom jeziku. Prvi deo: slaganje i prefiksacija. Beograd: Zavod za udžbenike i nastavna sredstva, Institut za srpski jezik SANU.

Kluge, F. (1989). Etymologisches Wörterbuch der deutschen Sprache (22. Aufl.). Berlin/New York: De Gruyter.

Köbler, G. (1989). Gotisches Wörterbuch. Leiden. Preuzeto 25. 04. 2013, sa http://www.koeblergerhard.de/ahdwbhin.html.

Köbler, G. (1994). Althochdeutsches Wörterbuch. Paderborn: Ferdinand Schönigh Verlag.

Krause, W. (1953). Handbuch des Gotischen. C.H. München: Beck 'sche Verlagsbuchhandlung.

Kühnhold, I. (1973). Deutsche Wortbildung: Typen und Tendenzen in der Gegenwartssprache. Düsseldorf: Schwann.

Langenscheidt (2001). Großes Schulwörterbuch Lateinisch-Deutsch. (e-Wörterbuch Lateinisch-Deutsch 4.0 [SW] Wörterbuch-Basis).

Lexer, M. (1912). Mittelhochdeutsches Wörterbuch. Leipzig: Verlag von S. Hirzel.

Meier-Brügger, M. (2000). Indogermanische Sprachwissenschaft (7., völlig neu bearbeitete Auflage). Berlin/New York: Walter de Gruyter.

Motsch, W. (2004). Deutsche Wortbildung in Grundzügen. 2., überarbeitete Auflage. Schriften des Instituts für Deutsche Sprache. Berlin: de Gruyter.

Mungan, G. (1986). Die semantische Interaktion zwischen dem präfigierten Verbzusatz und dem Simplex bei deutschen Partikel- und Präfixverben. Frankfurt am Main: Peter Lang.

Pudić, I. (1971). Gotski jezik i istorijska gramatika. Beograd: Zavod za udžbenike i nastava sredstva Srbije.

Ristić, S., \& Kangrga, J. (1963). Enzyklopädisches deutsch-serbokroatisches Wörterbuch (2. wesentlich verbesserte und erweiterte Auflage). München: Max Hueber Verlag/Beograd: Prosveta.

Rečnik srpskoga jezika (2007). Novi Sad: Matica Srpska.

Rein, K. (1983). Einführung in die Kontrastive Linguistik. Darmstadt: Wissenschaftliche Buchgesellschaft.

Stiebels, B. (1996). Lexikalische Argumente und Adjunkte: Zum semantischen Beitrag von verbalen Präfixen und Partikeln. Studia Grammatica, 39. Berlin: Akademie Verlag. 
Stevanović, M. (1964). Savremeni srpskohrvatski jezik. Gramatički sistemi i književnojezička norma. Beograd: Naučno delo.

Tellenbach, E. Neuhochdeutsche und neuniederlänische Bildungen mit dem Präfix VER-. In: Beiträge zur Geschichte der deutschen Sprache und Literatur. (Haale/Saale). 1976. Band 96. p. 2-63.

Wahrig (2009). Richtiges Deutsch leicht gemacht. Bertelsmann.

Иштван Богнер, Сања Нинковић

\title{
СЕМАНТИКА ГЛАГОЛСКОГ ПРЕФИКСА VER- У САВРЕМЕНОМ НЕМАЧКОМ ЈЕЗИКУ И ЊЕГОВИ ЕКВИВАЛЕНТИ У СРПСКОМ ЈЕЗИКУ
}

\section{РЕЗИМЕ}

Прилог се бави семантиком префикса ver- код немачких глагола и његовим еквивалентима у српском језику. На основу одабраног корпуса анализирају се тзв. „ver-Verben“ (verглаголи) и сврставају се, у зависности од њихове семантичке функције, у девет група. Закључци и подаци у вези са сличностима и разликама њихове семантике до којих се долази захваљујући паралелним упоређивањем корпуса у оба језика, доприносе бољем разумевању глагола са префиксом ver-, те би резултати који проистичу из овог прилога могли да се користе у настави немачког као страног језика.

Ištvan Bogner, Sanja Ninković

\section{THE SEMANTICS OF THE GERMAN VERBAL PREFIX VER- AND HIS EQUIVALENTS IN SERBIAN}

\begin{abstract}
SUMMARY
This paper deals with the German verbal prefix ver-and its semantics, compared to the Serbian equivalents. A contrastive analysis between these two languages shows that there are many similarities, but also some differences between the German prefixal ver-verbs and their Serbian equivalents. Based on a comprehensive corpus, all ver-verbs have been classified in nine semantic groups. Since prefixal verbs cause GFL-students many problems, it is the aim of this paper that all conclusions and facts that result from this parallel comparison should be a contribute to a better understanding of German as a foreign language.

Keywords: semantics, verbs, prefix, ver-, German-Serbian.
\end{abstract}

